\title{
PEQUENAS E MÉDIAS EMPRESAS BRASILEIRAS: PROPOSIÇÃO DE UM MODELO COMPORTAMENTAL EVOLUTIVO PARA A INTERNACIONALIZAÇÃO DE FIRMAS DE HPPC
}

\author{
SMALL AND MEDIUM BRAZILIAN COMPANIES: PROPOSITION OF AN EVOLUTIONARY \\ BEHAVIORAL MODEL FOR THE INTERNACIOLIZATION OF HPPC FIRMS
}

\section{Ednaldo Soares}

Doutor em Administração pela Universidade Federal da Bahia (UFBA). Salvador (BA), Brasil

\section{Rodrigo Ladeira}

Doutor em Administração e professor da Escola de Administração da Universidade Federal da Bahia (UFBA). Salvador (BA), Brasil
Data de recebimento: 20-08-2014

Data de aceite: 29-01-2015

\section{RESUMO}

Estudos sobre a internacionalização de empresas surgiram a partir dos anos 1960. Este é um exemplo centrado em um grupo de pequenas e médias empresas brasileiras fabricantes de produtos de higiene pessoal, perfumaria e cosméticos (HPPC). Trata-se de um estudo (exploratório-descritivo ex-post facto) de casos múltiplos, conduzido sob abordagem qualitativa, em que representantes-chave das empresas foram entrevistados e cuja análise dos dados valeu-se, sobretudo, do conteúdo das narrativas a fim de verificar similaridades e dessemelhanças entre os processos de inserção global e entre eles e o Modelo de Uppsala. Ao final, verificou-se evidência de gradualismo, mas constatou-se, que as empresas não se valeram de um modelo específico de internacionalização. Destarte, o estudo propõe o uso de um modelo comportamental evolutivo para a internacionalização de pequenas e médias empresas brasileiras fabricantes de produtos de HPPC, sendo esse a resultante da aliagem entre estratégias utilizadas pelas empresas e características do mencionado modelo.

Palavras-chave: Pequenas e médias empresas; internacionalização de empresas; modelo de Uppsala; modelo comportamental evolutivo de internacionalização.

\section{ABSTRACT}

Studies about the internationalization of companies began to be made in the 1960's. This is another example focused on a group of small and medium-sized Brazilian manufacturers of cosmetics, toiletry and perfumes. It is an exploratory and descriptive ex-post facto research, conducted under a qualitative approach to investigate internationalization processes through interviews with the companies' key representatives, whose data analysis drew on particularly content analysis of the narratives in order to ascertain similarities and differences between the investigated internationalization processes, and between those and the Uppsala Model. At the end, there was evidence of gradualism, but it was also found that the companies have not used a specific model to internationalize. Therefore, the study proposes the use of an evolutionary behavioral model for the internationalization of small and medium-sized Brazilian manufacturers of cosmetics, toiletry and fragrance which stems from the alliance between strategies used by the firms and the Uppsala Model's characteristics.

Keywords: Small and medium-sized companies; internationalization of companies; Uppsala model; internationalization evolutionary behavioral model. 


\section{INTRODUÇÃO}

A partir da criação do General Agreement on Tariffs and Trade (GATT) em 1947, as barreiras existentes no comércio internacional têm diminuído, e percebe-se que o atual cenário globalizado tem facilitado a inserção internacional de empresas. Também merece destaque o fato de que a inserção global de empresas tem sido facilitada pelo desenvolvimento de novos instrumentos financeiros criados a partir de meados dos anos 1970, decorrentes de mudanças de longo alcance nos mercados financeiros das economias industriais avançadas e de fatores inter-relacionados, tais como: a progressiva desregulamentação desses mercados nos países líderes e sua posterior internacionalização; a introdução de um conjunto de novos instrumentos financeiros, permitindo maiores e mais arriscados investimentos desse gênero; e o surgimento do crescente papel de novos atores no mercado, particularmente de investidores institucionais (COSH et al.,1992). Uma vez que o fenômeno está relacionado com aspectos comportamentais na gestão das organizações, ele não se restringe à grande corporação, mas pode ser perseguido por firmas de pequeno e médio porte (PMEs).

Resultante de decisão organizacional, a internacionalização de empresas visa a ampliação de mercado, a aquisição de recursos, a diversificação de compradores e fornecedores, a minimização de risco competitivo e o crescimento da empresa (DANIELS; RADEBAUGH, 1998). Por conseguinte, do ponto de vista socioeconômico, auxilia um país a melhorar em vários aspectos, entre os quais se inclui a potencialidade para promoção de aumento nos níveis de renda, de emprego e de inclusão social.

A internacionalização é um processo por meio do qual uma empresa mantém operações crescentes com o exterior, em virtude da aquisição de conhecimento e comprometimento com os mercados externos (JOHANSON; VAHLNE, 1977, 2009), que se manifestam de várias maneiras: exportação (abertura para relacionamentos de dentro para fora - outward connections); importação (abertura para relacionamentos de fora para dentro inward connections); investimentos diretos no exterior (ex:: greenfield investment); acordos de licenciamento (ex.: licenciamento de tecnologia); franchising; formação de joint ventures; além de outros modos mais complexos como a aquisição de empresas estrangeiras ou o estabelecimento de novas subsidiárias (MADURA, 2011). É, portanto, um processo de adaptação da empresa a mercados externos, valendo-se de estratégias e de outros recursos. Por conseguinte, uma empresa internacional é "uma organização caracterizada por processos cumulativos de aprendizagem e que apresenta uma complexa estrutura de recursos, competências e influências" (HEMAIS; HILAL, 2003, p.10).

Quando, porém, esse fenômeno se torna preocupação do governo, isso ajuda no desenvolvimento de projetos para a nação, que, entre outros propósitos, incluem a geração de empregos (KIRK, 2011) e a competitividade do país (KATZ; BRADLEY, 2010). Assim, por um lado, ao voltarem-se à internacionalização, as PMEs contribuem para o alcance de objetivos relacionados ao desenvolvimento econômico nacional/regional. Por outro lado, a influência ideológica exercida sobre políticas de desenvolvimento convence o governo e outros atores sociais de que o desenvolvimento econômico nacional depende da internacionalização de empresas (ALBUQUERQUE LLORENS, 2001), e isso impulsiona muitos países a promoverem programas de inserção de empresas nacionais no mercado externo.

\subsection{O setor brasileiro de HPPC: a experiência exportadora das empresas integrantes do Beautycare Brazil e sua escolha como foco do estudo}

A escolha do setor de HPPC como foco deste estudo deve-se aos seguintes aspectos econômicos: 
segundo a Associação Brasileira da Indústria de Higiene Pessoal, Perfumaria e Cosméticos (Abihpec) (2010), nos últimos 14 anos, essa indústria teve crescimento médio de 10,5\% contra o de 2,3\% da indústria geral e o de 2,9\% do PIB total. Entre 2000 e 2009, houve crescimento acumulado de $249,7 \%$ das exportações brasileiras desses produtos. Até 2001, a balança comercial do setor era deficitária, tornando-se superavitária a partir de 2002 e, apesar da crise mundial de 2008, apresentou superávit de US\$131 milhões, em 2009. Ademais, entre 1994 e 2009, a geração de oportunidades de trabalho promovida pelo setor (incluídos os subsetores: indústria, franquia, consultoria de venda direta e salão de beleza) cresceu 222,50\%.

Não obstante, um levantamento da Abihpec (2011) mostrou um total de 1.659 empresas nacionais atuando no setor, sendo apenas 14 delas de grande porte. Apesar de ser um grande produtor e das exportações de HPPC apresentarem crescimento, comparando o Brasil com os maiores países-exportador, ele ocupa a $22^{a}$ posição, atrás do México, da Tailândia e da Índia (TEIXEIRA JR. et al., 2012). Contudo, sendo a maioria das empresas do setor pertencente ao segmento PME, isso justifica sua escolha como foco do estudo. Além disso, a escolha deveu-se, também, ao fato de que as exportações das integrantes do Beautycare Brazil superam o crescimento geral do setor (BEAUTYCAREBRAZIL, 2011).

\section{ASPECTOS METODOLÓGICOS}

Sem se ater à questão da influência ideológica, como objetivo geral, este estudo buscou resposta ao seguinte questionamento: Como pequenas e médias empresas (PMEs) brasileiras fabricantes de produtos de higiene pessoal, perfumaria e cosméticos (HPPC) se internacionalizam - consoante um modelo específico ou através de estratégias diferenciadas?

Na falta de um roteiro-padrão, o objetivo específico se preocupou em propor um modelo comportamental evolutivo para a internacionalização de PMEs fabricantes de HPPC, tendo como referências o Modelo de Uppsala (1977: criação; 2009: "revisita") e as experiências das empresas analisadas.

Alguns pontos do estudo, no entanto, necessitam de esclarecimentos: em primeiro lugar, que o critério para enquadrar empresas no estrato das PMEs considerou o número de empregados conjugado com o faturamento, conforme os dados da Tabela 1; em segundo, que a exportação foi a única via de internacionalização considerada, devido às poucas exigências relacionadas com recursos organizacionais e pelo baixo risco negocial que ela traz em si (GAO et al., 2009); e, por último, que este é um estudo (exploratório-descritivo ex-post facto) de casos múltiplos, conduzido

Tabela 1: Critérios de estratificação de empresas segundo o tamanho

\begin{tabular}{|c|c|c|c|}
\hline \multirow[t]{2}{*}{ Classificação } & \multirow{2}{*}{$\begin{array}{l}\text { Receita Operacional Bruta } \\
\text { Anual (BNDES) }\end{array}$} & \multicolumn{2}{|c|}{$\begin{array}{c}\text { Número de Empregados } \\
\text { (Sebrae) }\end{array}$} \\
\hline & & Indústria/construção/outros & Comércio/serviços \\
\hline Micro empresa & $\leq \mathrm{R} \$ 2,4$ milhões & 0 a 19 & 0 a 9 \\
\hline Pequena empresa & $\begin{array}{l}>R \$ 2,4 \text { milhões e } \\
\leq R \$ 16 \text { milhões }\end{array}$ & 20 a 99 & 10 a 49 \\
\hline Média empresa & $\begin{array}{l}>\mathrm{R} \$ 16 \text { milhões e } \\
\leq \mathrm{R} \$ 90 \text { milhões }\end{array}$ & 100 a 499 & 50 a 99 \\
\hline Média-grande empresa & $\begin{array}{l}>\mathrm{R} \$ 90 \text { milhões e } \\
\leq \mathrm{R} \$ 300 \text { milhões }\end{array}$ & 100 a 499 & 50 a 99 \\
\hline Grande empresa & $>\mathrm{R} \$ 300$ milhões & mais de 500 & mais de 100 \\
\hline
\end{tabular}

Fonte: Elaboração do autor com base no Sebrae (2011) e no BNDES (2011). 
sob abordagem qualitativa, em que se procurou investigar os processos de inserção global de empresas do segmento PME filiadas ao projeto Beautycare Brazil, criado pela Abihpec em parceria com a Agência Brasileira de Promoção de Exportações e Investimentos (Apex-Brasil), cujo propósito é internacionalizar produtos e marcas brasileiras de HPPC. Foram feitas entrevistas com representantes-chave de cinco firmas e com os atores envolvidos no projeto (um público e outro privado), análise documental, visitas aos sites das empresas analisadas, visitas aos sites de outras empresas integrantes do referido projeto e aos sites das citadas organizações. A análise dos dados valeu-se da análise de conteúdo das narrativas, a fim de verificar similaridades e dessemelhanças entre os processos, e entre eles e o Modelo de Uppsala (referencial teórico do estudo). Salientase ainda que as empresas analisadas eram regularmente ativas no comércio exterior há pelo menos um ano, quando a pesquisa foi iniciada; ou seja, são firmas que exportam, direta ou indiretamente e de forma contínua, produtos de sua fabricação.

Sabe-se que a maioria das empresas brasileiras do setor de cosméticos com melhor desempenho exportador filia-se a uma associação voltada à promoção das exportações desses produtos. A esse fato deve-se a escolha de PMEs filiadas ao Beautycare Brazil, pois, de modo geral, essas empresas têm obtido resultados superiores aos das demais empresas do ramo (BEAUTYCAREBRAZIL, 2011).

Contrariando a intenção original de se fazer uma pesquisa censitária com as PMEs (com comprovada experiência exportadora) filiadas ao projeto supracitado, apenas seis se dispuseram a cooperar com o estudo. No entanto, em 2012, quinze empresas integravam o Beautycare Brazil; sendo duas delas empresas de grande porte, e as outras treze do grupamento PME (considerando apenas as "divisões" autônomas encarregadas da produção de cosméticos, pois duas dessas firmas integram grupos empresariais distintos e de grande porte).

Das treze, apenas dez operavam no comércio exterior (primeiro estágio do processo de internacionalização: exportação indireta e/ou direta) há no mínimo um ano. Apesar de todas terem sido contatadas, apenas seis, conforme menção anterior, decidiram participar da pesquisa, indicando representantes para serem entrevistados.

As seis empresas foram entrevistadas mas, posteriormente, uma delas foi descartada, pois, apesar de ser de pequeno porte, de ter razão social própria e gestão independente, trata-se de uma das 15 business units de um conglomerado com larga experiência em comércio exterior, tendo sido criada para produzir produtos HPPC exclusivamente para exportação. Para inserir-se nos mercados externos, a empresa tem contado com as subsidiárias do Grupo estabelecidas no exterior. Trata-se, portanto, de uma bornglobal firm, fato que a afastou do escopo da pesquisa.

O estudo procurou compreender os processos de internacionalização das empresas analisadas consoante às narrativas dos entrevistados e outras evidências secundárias (relatórios e documentos comprobatórios da atividade exportadora). Para tanto, os aspectos históricos relativos à origem das decisões pró-internacionalização das firmas foram considerados, ou para se manterem atualmente no mercado internacional e/ou planejarem ou perseguirem suas expectativas futuras quanto à atuação no comércio exterior. Um misto de questões fechadas e abertas foi utilizado para motivar/direcionar as narrativas dos entrevistados, a fim de atender o interesse da pesquisa. Salientase também, que, conforme esclarecimento dado por Duarte (2002, p. 140) a respeito de entrevista semiestruturada, as perguntas não foram (na verdade não precisam ser) "nem um pouco originais".

A análise de conteúdo das narrativas considerou de maneira ampla duas dimensões-foco: 
1) gradualismo ou processo incremental (importância dada pelas firmas a variáveis, tais como: mercado similar, cultura negocial similar, conhecimento do mercado e consciência cultural, ou seja, a atenção dada à distância psíquica/cultural na escolha de mercados-alvo); cadeia de estabelecimento;

2) inovações (incluindo o engajamento das empresas em redes - networking), considerando a diferenciação de produtos como indicador.

\section{REFERENCIAL TEÓRICO: O MODELO DE UPPSALA}

As decisões da empresa relativas ao seu comprometimento com os mercados externos (quantidade de recursos e grau de interesse da empresa em determinado país) e ao próprio conhecimento de suas atividades cotidianas e dos mercados-alvo são os fundamentos do Modelo de Uppsala (JOHANSON; VALHNE, 1977). O modelo (em sua versão original) considera que a inserção global da firma se dá de forma gradual, em consequência do aprendizado de como se relacionar com os mercados externos (JOHANSON; VAHLNE, 1977; TREVISAN, 2009), cuja escolha sequencial ocorre de acordo com a percepção de proximidade dos mercados forâneos com o mercado doméstico (FORSGREN; HAGSTRÖM, 2005). Também, que o uso de uma abordagem evolutiva no processo de internacionalização reduz os riscos da empresa (JOHANSON; VAHLNE, 1977; HANSSON et al., 2004). Ou seja, que o gradualismo se relaciona com dois aspectos: (1) conhecimento da empresa acerca das operações, dos mercados estrangeiros e dos recursos comprometidos com esses mercados (aspectos circunstanciais); e (2) decisões para comprometer os recursos e desempenho corrente das atividades do negócio da empresa (aspectos mutáveis). Ambos os aspectos exercem influências recíprocas (JOHANSON; VALHNE, 1977).

Ainda segundo o modelo, os estágios do aprendizado (cadeia de estabelecimento) começam com exportações esporádicas e progridem para frequentes, intermediadas por agentes. Em seguida, já frequentes, a empresa passa a procurar os próprios clientes mediante contatos negociais diretos. Algumas chegam a abrir escritórios comerciais ou até a implantar unidades produtivas no exterior (JOHANSON; VALHNE, 1977).

A respeito da cadeia de estabelecimento, corroboram Chiao e Yang (2011) quando se referem à sigmoide proposta por alguns pesquisadores para definir a relação entre o desempenho da empresa e a internacionalização. A sigmoide é dividida em quatro estágios preliminary stage, early stage, mid-stage e late stage -, e cada um deles é caracterizado pela inclinação da curva, isso é: positiva, no preliminar stage; negativa, no early stage; positiva, no mid-stage; e negativa, no late stage (devido a fatores que ocorrem em cada um deles).

Ao final do estudo, Chiao e Yang (2011) concluíram que, em economias de industrialização recente (EIRs), empresas internacionalizadas cedo percorrem apenas os dois primeiros estágios da curva, ou seja, exportação indireta ${ }^{1}$ e exportação direta. ${ }^{2}$

Outro quesito considerado importante no momento de criação do Modelo de Uppsala

\footnotetext{
Primeiro estágio: parte da sigmoide em que a inclinação é positiva devido aos benefícios inerentes a esse tipo de transação.

2 Segundo estágio: com inclinação negativa da curva, em virtude dos custos inerentes à exportação direta: custos de comunicação e coordenação; de sujeição à suscetibilidade, por tratar-se de empresa estrangeira operando em mercados externos (liability of foreignness); aprendizagem inicial sobre custos de investimentos diretos no estrangeiro (IDE); economias de escala insuficientes; e aumento dos custos devido à mudança no modo de internacionalização.
} 
diz respeito à distância psíquica, isto é, ao conjunto de fatores (cultura, distância geográfica entre os países envolvidos em transações comerciais, aspectos linguísticos e religiosos, comércio pré-existente, relações diplomáticas, origem da população, herança de colonização etc.) que dificultam o entendimento dos mercados estrangeiros, mas ao mesmo tempo possibilitam indicar o grau de proximidade entre os mercados externos e o doméstico (JOHANSON; VALHNE, 1977). Essa distância tem quatro dimensões - cultural, administrativa, geográfica e econômica (CAGE) - e sua não avaliação pormenorizada pode custar o insucesso da entrada da empresa em um mercado específico (GHEMAWAT, 2001; 2010). Isso porque exportações para países psiquicamente próximos garantem maior sucesso da expansão global da empresa.

Apesar de alguns pesquisadores (LARIMO, 2003; KUO; FANG, 2009) concordarem com a importância do gradualismo e/ou da distância psíquica para a internacionalização da empresa e para a aquisição de experiência no mercado doméstico antes de se inserir no mercado global, outros discordam. Primeiro, por considerar que a elaboração do Modelo de Uppsala ocorreu em uma época menos turbulenta que a atual (REZENDE, 2004); segundo, por constatar que muitas empresas queimam estágios (FORSGREN; HAGSTRÖM, 2005), pois entendem que, para manter a competitividade, precisam buscar no exterior não apenas mercados potenciais, mas também fontes mais baratas de mão de obra e matéria prima de alta qualidade (ROWDEN, 2001).

Devido às críticas, Johanson e Vahlne (2009) revisitaram o modelo e admitiram ter negligenciado aspectos enfatizados em estudos mais recentes. É o caso da pouca atenção dada às estratégias baseadas em custo e diferenciação (AULAKH et al., 2000), ou da relevância do papel das redes (networks) e seus impactos na escolha dos mercados e no modo como inserir-se neles. Desde então, o modelo admite que a internacionalização da empresa é um processo de construção de posicionamento em uma rede pertencente a um mercado externo visando a aprendizagem, a construção de confiança, a identificação e a exploração de oportunidades e o desenvolvimento de comprometimentos (JOHANSON; VAHLNE, 2009).

Para a atual concepção do Modelo, o relacionamento em rede tornou-se importante para a firma se internacionalizar, uma vez que parceiros de relacionamento são fontes relevantes de informação negocial sobre seus próprios parceiros e atores mais distantes na rede.

Em síntese, para Johanson e Vahlne (2009), atualmente, a empresa é uma entidade de negócio voltada em primeiro lugar à atividade de troca (aspecto que define uma empresa para além da produção, pois o valor da produção é entendido com um advento oriundo da troca). Ademais, para esses pesquisadores, o ônus passível de ser carregado pela empresa internacionalizada atualmente não é mais o de ser estrangeira (liability of foreignness), mas de não estar engajada em redes que lhe permitam a exploração de oportunidades (liability of outsidership). Ou seja, esse ônus tornou-se a raiz da incerteza mais do que a distância psíquica antes representava (JOHANSON; VAHLNE, 2009).

\section{ESTUDO DOS CASOS: APRESENTAÇÃO E ANÁLISE DE DADOS}

Neste tópico, estão descritas as características dos processos de internacionalização de cinco empresas integrantes do Beautycare Brazil. Consoante acordo, os nomes das empresas e dos entrevistados foram 
omitidos - em vez de suas razões sociais, nomes de letras do alfabeto grego foram utilizados para identificação.

A título de complementação do que se mencionou acerca do referido projeto, acrescentam-se as seguintes informações: o propósito do Beautycare Brazil é a internacionalização de marcas nacionais de HPPC, a fim de torná-las internacionalmente relevantes. Sua estratégia inclui as seguintes atividades: participação das empresas em workshops e feiras internacionais, especificamente as mais bem classificadas (que ocorrem nas cidades de Bolonha, Dubai e Las Vegas); com o apoio da Apex-Brasil, montagem de stands em feiras para as afiliadas; e promover rodadas de negócios.

Além da citada parceria, atualmente o projeto recebe apoio do Serviço Brasileiro de Apoio às Micro e Pequenas Empresas (Sebrae), do Instituto de Tecnologia e Estudos de Higiene Pessoal, Perfumaria e Cosméticos (ITEHPEC) e da Agência Brasileira de Desenvolvimento Industrial (ABDI).

\subsection{Sinopses das narrativas dos representantes-chave das empresas: análise individualizada dos casos}

Nos subitens abaixo, estão registradas as análises individualizadas dos casos, a partir das entrevistas com duração média de duas horas e da leitura de documentos de exportação (arquivos de faturas emitidas, de contratos de câmbio de exportação fechados e/ou liquidados, de pedidos dos importadores etc.).

\subsubsection{Empresa Alpha}

Representante-chave: Gerente de exportação. Empresa de porte médio, criada em 1997. Embora tenha razão social própria e gestão autônoma, a
Alpha integra uma organização de grande porte. Em 2011, começou a exportar para Moçambique país psíquica e culturalmente próximo ao Brasil (mesmo idioma e origem colonizadora). A escolha do país se deu pelo conhecimento de que já importava produtos HPPC de concorrentes brasileiros. Atualmente, a empresa exporta para Angola, Cabo Verde, Arábia Saudita, Emirados Árabes Unidos, Chile, México e Venezuela (nem todos são países "próximos" do Brasil, o que mostra a desatenção ao quesito distância psíquica).

A Alpha contata diretamente os distribuidores nos citados mercados e apresenta os produtos, visando a colocação posterior. Os distribuidores constituem as redes nas quais a Alpha se encontra inserida; porém, com vistas à permanente promoção de seus produtos no exterior e conquistas de novos mercados, a empresa tem participado de feiras e rodadas de negócios no Brasil e fora dele.

Segundo o entrevistado, o conglomerado do qual a Alpha faz parte, "é uma das organizações brasileiras que mais investe em pesquisa e desenvolvimento (P\&D)". Na empresa, prevalece a inovação de produto, feita tanto de modo incremental, quanto radical, com o uso de nanotecnologia.

Considerando planos futuros, a Alpha tem feito parcerias com similares nos EUA, na Alemanha, na Itália, na Inglaterra, no Japão, na Índia e na Suíça, sempre em busca de inovação. Portanto, sendo a inovação uma vantagem competitiva, na prática, seu exercício pela Alpha tem contribuído para o sucesso de sua inserção global e conquista de novos mercados.

No que diz respeito ao apoio governamental, a empresa tem contado com o suporte dos Setores Comerciais (SECOMs) das Embaixadas brasileiras localizadas nos países de seus compradores e com o apoio da Apex-Brasil. Os SECOMs fornecem contatos de possíveis compradores externos e o suporte da Apex-Brasil tem servido para reduzir custos com viagens ao exterior para participar de feiras. 


\subsubsection{Empresa Beta}

Representante-chave: Analista-chefe de exportação (Departamento de vendas).

Empresa de porte médio, a Beta começou a exportar em 2005. Tratando-se de empresa comprometida com a conquista de mercados, a Beta enxergou na exportação uma estratégia de internacionalização. E, dado que seus produtos são de boa qualidade, a empresa decidiu participar de feiras nacionais de HPPC. Nessas participações, recebeu propostas de compradores estrangeiros e iniciou a operar no comércio internacional. Primeiramente, via trading company, exportou creme capilar embalado em vasos de $1 \mathrm{~kg}$ para a Arábia Saudita país psíquica e culturalmente distante do Brasil, o que também comprova a falta de preocupação da empresa com a distância psíquica.

A proposta externa estimulou o processo de internacionalização da Beta, que passou a se utilizar de traders para enviar amostras de produtos para possíveis compradores externos e a participar de rodadas de negócios no exterior. Devido a essas iniciativas, os produtos da Beta hoje são exportados para EUA, México, Colômbia, Equador, Índia, Arábia Saudita, Portugal, Itália, Turquia e Austrália. Também podem ser encontrados em Angola e Cabo Verde, para onde são reexportados de Portugal e em alguns países do Caribe.

Na América Latina, o grosso das exportações da Beta destina-se ao Equador e à Colômbia. Na América do Norte, os EUA e o México, por enquanto, têm comprado pequenas quantidades (a documentação da Secretaria de Comércio Exterior - SECEX mostra que, em 2010, o montante de exportações da empresa para os EUA foi de US\$13,7 milhões FOB).

A Europa é o segundo polo importador da Beta, sendo Portugal o maior comprador. Porém, no total das vendas externas, o Oriente Médio é o maior polo comprador da empresa e o atual destino de 50\% de suas exportações. Ali, a Arábia Saudita é o maior comprador, à frente da Índia.
Em busca de ampliação de mercado, merece destaque o modo (cadeia de estabelecimento) utilizado pela Beta para inserir-se internacionalmente. Desde o princípio, suas exportações têm sido intermediadas sendo as únicas exceções as exportações para a Colômbia e a Índia, que são feitas por contatos diretos com importadores locais.

Muitas têm sido as adaptações nos produtos exportados pela Beta para atender exigências de importadores. Algumas dizem respeito ao uso (ou não) de certas substâncias nas fórmulas; outras estão relacionadas à rotulagem, isto é, dizem respeito aos idiomas utilizados nas embalagens.

O entrevistado salientou que as exportações de HPPC para a União Europeia devem seguir diretrizes da EU Cosmetics Directive, a fim de evitar problemas no desembaraço aduaneiro, ou posteriores ações judiciais promovidas pela Cosmetics Europe - The Personal Care Association, caso algum produto infrinja a norma reguladora. Também, que as exportações para países árabes devem ter rótulos em árabe, inglês e/ou francês e que, para o desembaraço de mercadorias na Arábia Saudita, exige-se a apresentação do documento denominado Certificate of Conformity for Exports to Saudi Arabia, conhecido como SASO COC.

Para adaptar fórmulas, a empresa precisou criar o departamento de P\&D. Em geral, a inovação de produto acontece de forma incremental, mas não raro, radicalmente. Inovações ou o uso de know-how (a exemplo do utilizado na linha para alisamento capilar) são o que diferenciam os produtos da Beta de similares e promovem aceitação externa. A empresa também utiliza métodos e maquinário modernos para melhorar a produção e reduzir os custos (inovação de processo).

A Beta diz não se sentir completamente inserida em redes de relacionamento, uma vez que suas vendas ficam a cargo de agentes e seus contatos diretos são limitados a poucos compradores. Além das vendas por meio de agentes, a empresa participa de feiras no Brasil e é representada por seus 
agentes em feiras externas. Porém, a Beta planeja transformar as exportações indiretas em diretas, à medida que seus produtos se solidifiquem na preferência dos países importadores; fato que confirma o reflexo do gradualismo em sua cadeia de estabelecimento, conforme prevê o Modelo de Uppsala.

Com relação ao apoio do governo brasileiro, a empresa afirma contar muito pouco com esse suporte. No entanto, alguns importadores exigem o certificado de origem de seus produtos, a fim de obterem incentivos fiscais em seus países; com isso, os produtos da Beta se tornam mais competitivos do que os de outras marcas importadas de países avançados.

No início, a Beta só exportava mediante pagamento antecipado. Atualmente, exporta na modalidade de cobrança documentária à vista, ou com pagamento através do site http://www.paypal.com.

\subsubsection{Empresa Delta}

Representante-chave: Sócio proprietário.

Empresa média, fundada em 1993 com a finalidade de produzir cosméticos para salões de beleza. Embora de modo não planejado, mas estimulada pela demanda de visitantes estrangeiros em feiras no país, a Delta começou seu processo de internacionalização em 2010, exportando diretamente, primeiro para Moçambique - país psíquica e culturalmente próximo do Brasil. Desde então, passou a buscar outros mercados valendo-se de distribuidores. Para alguns países, no entanto, a Delta exporta diretamente.

Os produtos da Delta são atualmente exportados para: Chile, Canadá, Itália, França, Bulgária, Eslovênia, Croácia, Turquia, Romênia e Moçambique; por essa razão, as embalagens de seus produtos têm rótulos em português, espanhol e inglês. Essa foi uma das adaptações feitas para atender exigências externas.

Com relação ao quesito inovação, a empresa tem criado novas fórmulas, mas também se vale de inovação de processo, que não se limita aos quesitos tecnológicos aplicados na fabricação apenas para manter o estado da arte, mas está também associada ao uso do produto; ou seja, a inovação vincula-se à promoção de melhorias no modo de aplicar os cosméticos e ao tempo de duração.

O entrevistado relatou que, "no mercado atual não há um produto radicalmente diferente dos similares, a ponto de se tornar milagroso". Portanto, semelhantes aos produtos da Delta, existem outros produzidos nos países compradores, ou importados de concorrentes brasileiros e estrangeiros. Sendo assim, a empresa procura se diferenciar por meio da associação de matérias primas e da facilitação do modo de aplicá-los.

Visando a ampliação de mercado, a empresa participa de feiras no Brasil e de rodadas de negócios no exterior. Os planos para o futuro contemplam incremento das exportações, a ampliação dos atuais e a conquista de novos mercados. Afora a própria iniciativa de expandir-se globalmente, a empresa conta com o apoio do Beautycare Brazil e da Apex-Brasil para participar de feiras no exterior.

\subsubsection{Empresa Pi}

Representante-chave: Coordenador-executivo do setor de exportação.

Empresa de médio porte, fundada em 1975 e internacionalizada em 2002, de modo planejado, contando com estímulo externo. As primeiras exportações, destinadas aos Emirados Árabes Unidos, foram efetuadas indiretamente. Com o tempo, começou a exportar diretamente para varejistas e grandes distribuidores. Isso confirma o gradualismo de seu processo de internacionalização, que partiu da exportação indireta para a direta. E, como as demais empresas analisadas, a Pi não tem tido preocupação com o quesito distância psíquica. Atualmente, a empresa exporta para 47 países.

Seu atual maior mercado importador é o oriente asiático, onde o Irã e a cidade-emirado de Dubai 
(compradora de $30 \%$ das exportações da Pi) se destacam. Outros mercados são países da América do Sul, com Bolívia, Colômbia, Peru e Uruguai sendo os maiores importadores. A empresa também exporta indiretamente (via distribuidores) e em pequena escala para os EUA. A Pi não utiliza agentes.

Assim como as demais firmas analisadas, os produtos da Pi sofreram adaptações em suas fórmulas e seus rótulos. As exigências dos mercados estimularam sua criatividade inovadora: novos produtos foram criados e novas tecnologias foram incorporadas ao processo produtivo. No entanto, a inovação de produto é a que mais demanda o esforço criativo da Pi, que ocorre de maneira incremental. Detentora de know-how utilizado na produção de creme para hidratação capilar, a fórmula secreta diferencia esse produto dos similares nacionais.

A empresa participa de feiras no país e no exterior. Para o futuro, planeja criar centros de distribuição próprios nos EUA e nos Emirados Árabes Unidos. No que tange ao apoio governamental, a firma tem recorrido ao incentivo fiscal Drawback ${ }^{3}$ e tem participado do Projeto Carnaval ${ }^{4}$ da ApexBrasil, o qual visa a promoção de negócios, atraindo potenciais compradores e investidores estrangeiros, aproveitando-se da visibilidade do carnaval brasileiro.

\subsubsection{Empresa Ômega}

Representante-chave: Diretor.

\footnotetext{
3 Regime Aduaneiro Especial concedido na forma de incentivo às exportações por meio de vantagens, tais como: suspenção ou isenção de taxas e impostos sobre os produtos importados para a fabricação de outros a ser ou que já foram exportados; dispensa de exame de similaridade nacional para efetuar a importação desses produtos; e dispensa da obrigatoriedade de transporte sob bandeira brasileira (observada a legislação específica).

4 Para mais detalhes, ver Carnaval Brasil: Business and Partnership. Disponível em: http://www.businessand partnership.com/carnaval.
}

Empresa de porte médio, fundada em 2001 com o propósito de inovar o mercado de cosméticos com a implantação de um Sistema de Gestão da Qualidade (SGQ), relacionado com a produção e os serviços. Fez a primeira venda externa para Dubai, de maneira direta.

A motivação exógena para a empresa se internacionalizar está relacionada com dois motivos: (1) a reputação que os cosméticos brasileiros detêm no Oriente Médio; e (2) o nível da taxa de câmbio (à época considerado sustentável para a empresa empreender transações internacionais).

Após a primeira exportação, feita diretamente, a Ômega expandiu as vendas para outros países do Oriente Médio, da África e da América Latina. Os produtos exportados pertencem às seguintes linhas: (1) uso oral (enxaguatórios e antissépticos bucais, fios e escovas dentais); e (2) uso corporal (xampus, restauradores capilares, desodorantes roll-on, sabonetes líquidos, sabonetes íntimos para homens e mulheres, géis, condicionadores e loções corporais), muitos dos quais foram adaptados aos mercados compradores.

Apesar da boa qualidade, os produtos da Ômega são classificados como "populares". Em parte, isso se deve a sua política de preços agressiva, que torna seus produtos mais competitivos. Esse enquadramento também desonera a empresa de apresentar documentação complexa para fins de liberação no mercado externo, incluindo a não exigência de detalhes das fórmulas nos rótulos. Segundo o entrevistado, isso ocorre conforme acordos multilaterais.

A empresa se diz engajada em redes externas formadas por compradores e distribuidores e participa de feiras e rodadas de negócios no exterior. Ademais, a Ômega exporta parte da produção com rotulagem específica utilizando razão social ou marca de terceiros, isto é, vale-se do instituto 
Quadro I: Características dos processos de internacionalização analisados

\begin{tabular}{|c|c|}
\hline Empresa & Características \\
\hline Alpha & $\begin{array}{l}\text { Iniciativa: endógena (estímulo: concorrência doméstica). } \\
\text { Exportação: direta. } \\
\text { Networking: distribuidores (promoção de vendas); parcerias externas. } \\
\text { Inovação de: produto (incremental e radical); processo. } \\
\text { Distâncias: sem registro. } \\
\text { Governo (apoio): informação (SECOMs); indireto via projeto Beautycare Brazil. } \\
\text { Outros: participação em feiras e rodadas de negócios; adaptação dos produtos às exigências externas. }\end{array}$ \\
\hline Beta & $\begin{array}{l}\text { Iniciativa: endógena (ação planejada; estímulo: demanda externa). } \\
\text { Exportação: indireta (via traders) e direta. } \\
\text { Networking: contato direto com compradores e agentes (promoção de vendas). } \\
\text { Inovação de: produto e processo; know-how. } \\
\text { Distâncias: sem registro. } \\
\text { Governo (apoio): sem registro (apenas indireto via projeto Beautycare Brazil). } \\
\text { Outros: participação em feiras; planos para transformar vendas indiretas em diretas; aceita pagamento on-line das } \\
\text { vendas; adaptação dos produtos às exigências externas. }\end{array}$ \\
\hline Delta & $\begin{array}{l}\text { Iniciativa: endógena (ação não planejada; estímulo: demanda externa). } \\
\text { Exportação: direta. } \\
\text { Networking: distribuidores (promoção de vendas). } \\
\text { Inovação de: produto (incremental); diferenciação. } \\
\text { Distâncias: sem registro. } \\
\text { Governo (apoio): sem registro (apenas indireto via projeto Beautycare Brazil). } \\
\text { Outros: participação em feiras, adaptação dos produtos às exigências externas. }\end{array}$ \\
\hline $\mathrm{Pi}$ & $\begin{array}{l}\text { Iniciativa: endógena (ação planejada; estímulo: aceitação externa de marcas brasileiras de produtos de HPPC). } \\
\text { Exportação: indireta (via traders) e direta. } \\
\text { Networking: distribuidores (promoção de vendas) e compradores. } \\
\text { Inovação de: produto (incremental) / design; processo; know-how. } \\
\text { Distâncias: sem registro. } \\
\text { Governo (apoio): Drawback (incentivo fiscal); Projeto Carnaval da Apex-Brasil; indireto via projeto Beautycare Brazil. } \\
\text { Outros: participação em feiras e eventos de negócios; adaptação dos produtos às exigências externas, criar centros de } \\
\text { distribuição próprios nos EUA e nos Emirados Árabes Unidos. }\end{array}$ \\
\hline Ômega & $\begin{array}{l}\text { Iniciativa: endógena (estímulo: demanda externa). } \\
\text { Exportação: direta. } \\
\text { Networking: contato direto com compradores. A empresa promove as vendas. } \\
\text { Inovação de: produto (incremental); processo; know-how. } \\
\text { Distâncias: sem registro. } \\
\text { Governo (apoio): sem registro (apenas indireto via projeto Beautycare Brazil). } \\
\text { Outros: participação em feiras; vendas externas na modalidade private label. }\end{array}$ \\
\hline
\end{tabular}

Fonte: Elabordo pelos autores

denominado no mercado como marcas próprias 5 (private labels) - expressão usada para denominar a produção de mercadorias de uma empresa que serão vendidas com a marca de outra.

A Ômega planeja continuar contando com o apoio do Beautycare Brazil e com o subsídio da Apex-Brasil para participar de feiras no exterior. 0 entrevistado ressaltou que ambas as organizações

\footnotetext{
5 Produção encomendada, devendo atender a especificações e a exigências da empresa compradora, detentora da marca com a qual a mercadoria será inserida no mercado.
}

foram facilitadoras do processo de internacionalização da Ômega, dando inclusive diagnósticos sobre a produção da empresa.

\section{DISCUSSÃO DOS RESULTADOS}

Neste tópico procede-se à discussão dos dados, que apontam as semelhanças e as diferenças entre os processos de internacionalização das empresas para confrontá-los com o Modelo de Uppsala. 


\subsection{Similaridades e dessemelhanças entre os processos de internacionalização das PMEs analisadas}

É semelhante o caráter endógeno das iniciativas empresariais relativas à decisão de se internacionalizar, mas as motivações não são uniformes. As ações iniciais dos processos também não são coincidentes, haja vista que algumas iniciativas ocorreram por acaso ou de forma não planejada (Alpha, Delta e Ômega), enquanto outras foram antecipadamente programadas (Beta e Pi).

A exportação direta é predominante. Há firmas, porém, que utilizam a via indireta, justificada pela redução de custos. Entretanto, é nesse tema (tipo de exportação, indireta ou direta, ou cadeia de estabelecimento), que se verificou a ocorrência de gradualismo no desenrolar dos processos estudados. Ressalta-se, no entanto, que vendas indiretas ou diretas são estratégias de exportação.

Ainda com relação ao gradualismo, ao iniciarem as vendas externas, as empresas analisadas não tinham muito conhecimento das operações em si, tampouco dos mercados estrangeiros para onde começaram a exportar; mesmo assim, todas comprometeram recursos com esses mercados. Isso implica afirmar que a falta de conhecimento dos mercados externos não foi um empecilho à internacionalização.

$\mathrm{Na}$ análise, chamou atenção a unânime desatenção das empresas ao quesito distância psíquica. Isso se deve, possivelmente, ao caráter universal do hábito do ser humano de fazer uso de produtos de HPPC, fato que parece tornar desnecessária a preocupação da empresa com essa questão. Também ficou claro que, com o auxílio do Beautycare Brazil, as empresas têm procurado se engajar em redes externas de relacionamento; em geral, essas redes são formadas por comerciantes, agentes e/ou distribuidores. No entanto, para se inserir em determinados mercados, algumas empresas têm assumido o risco da venda direta (ex.: Ômega).
Há de se ter em mente, que o engajamento da empresa no projeto Beautycare Brazil, per se, constitui-se um relacionamento em rede (doméstica), que oferece aos integrantes a oportunidade de aprender uns com os outros sobre a atividade exportadora e a negociação internacional. Cabe reiterar aqui algumas atividades desenvolvidas pelo projeto como parte da estratégia pró-internacionalização de suas afiliadas: promover a participação das afiliadas em feiras setoriais no exterior (especificamente as mais importantes: Bolonha, Dubai e Las Vegas); montar o pavilhão no qual os produtos das afiliadas são exibidos nessas feiras com apoio da Apex-Brasil; promover rodadas de negócios no estrangeiro; e organizar, no exterior, workshops para profissionais do setor. Além disso, o projeto proporciona às afiliadas uma série de aptidões voltadas à inserção global: gestão empresarial para exportação; capacitação técnica ambiental; negociação internacional; promoção internacional de exportações; inteligência e posicionamento; e promoção de imagem.

Ainda na análise, verificou-se a preocupação das empresas em adaptar seus produtos ao gosto dos países importadores, fato que ocorre por meio de iniciativas inovadoras. Em termos de preço, as empresas têm procurado tornar a oferta de seus produtos mais competitiva, valendo-se de inovação de processo feita de forma incremental ou radical e por meio do uso de know-how.

Quanto ao apoio governamental, a maioria das entrevistadas afirmou tê-lo recebido para participar de feiras no exterior. Porém, além desse suporte, a empresa Alpha mencionou o apoio de embaixadas brasileiras. A Pi foi a única a mencionar que valeu-se do Drawback e que participa do Projeto Carnaval. Quanto a planos futuros, apenas duas empresas evidenciaram seus objetivos claramente: uma pretende eliminar a intermediação das vendas externas; outra planeja criar centros de distribuição próprios nos EUA e nos Emirados Árabes Unidos. 
Quadro 2: Modelo de Uppsala vs. PMEs analisadas: importância das dimensões

\begin{tabular}{|c|c|c|c|c|c|}
\hline \multirow[b]{2}{*}{ Evento } & \multicolumn{2}{|c|}{ Gradualismo } & \multirow{2}{*}{$\begin{array}{c}\text { Inovação } \\
\text { Produto/ } \\
\text { Processo/ } \\
\text { Know-how } \\
\text { (incremental/ } \\
\text { radical) }\end{array}$} & \multirow{2}{*}{$\begin{array}{c}\text { Networking } \\
\\
\text { Distribuidores/ } \\
\text { Vendedores } \\
\text { finais/Agentes }\end{array}$} & \multirow{2}{*}{$\begin{array}{l}\text { Comprometimento } \\
\text { Com os mercados } \\
\text { externos }\end{array}$} \\
\hline & $\begin{array}{c}\text { Cadeia de } \\
\text { estabelecimento }\end{array}$ & $\begin{array}{l}\text { Proximidade MD } \\
\text { vs. ME }(*)\end{array}$ & & & \\
\hline Modelo de Uppsala & Importante & $\begin{array}{l}\text { Altamente } \\
\text { importante }\end{array}$ & Sem definição & $\begin{array}{l}\text { Altamente } \\
\text { importante }\end{array}$ & $\begin{array}{l}\text { Altamente } \\
\text { importante }\end{array}$ \\
\hline PMEs analisadas & Pouco importante & Sem importância & $\begin{array}{l}\text { Altamente } \\
\text { importante }\end{array}$ & $\begin{array}{l}\text { Altamente } \\
\text { importante }\end{array}$ & $\begin{array}{l}\text { Altamente } \\
\text { importante }\end{array}$ \\
\hline Obs. & $\begin{array}{l}\text { MD = Mercado } \\
\text { Doméstico }\end{array}$ & $\begin{array}{c}\left({ }^{*}\right) \text { Distâncias: } \\
\text { cultural e psíquica. }\end{array}$ & & & $\begin{array}{c}\text { ME }=\text { Mercado } \\
\text { Externo }\end{array}$ \\
\hline
\end{tabular}

Fonte: Elaborado pelos autores, baseado na análise das narrativas e no Modelo de Uppsala de Johanson e Vahlne (1977; 2009).

Apesar da similaridade de algumas ações pró -internacionalização das firmas analisadas, outras são dessemelhantes. O Beautycare Brazil, por sua vez, não impõe um modelo a ser seguido. O projeto cuida mais da organização de meios para promover produtos e marcas de suas afiliadas. Por conseguinte, afirma-se que essas empresas têm sido internacionalizadas mediante algumas estratégias comuns e outras díspares, sem que se configure um modelo.

\subsection{Similaridades e dessemelhanças entre os processos de internacionalização analisados e o Modelo de Uppsala}

O Quadro 2 resume as similaridades e as dessemelhanças entre o Modelo de Uppsala (original e "revisitado") e as PMEs analisadas. Quanto ao aspecto incremental (basilar para o Modelo de Uppsala original), verificou-se apenas no que respeita à cadeia de estabelecimento. A aprendizagem sobre os mercados externos e a distância psíquica entre eles e o mercado doméstico (questões previstas no Modelo de Uppsala original) não mereceram a atenção das empresas analisadas, mas não impediu que elas se inserissem globalmente. Verificou-se, entretanto, o comprometimento dessas empresas com os mercados externos (característica de ambas as versões do modelo).
Conforme os casos analisados, o gradualismo evidenciado no Modelo de Uppsala (1977) como redutor de risco teve sua importância diminuída. Dito e repetido, a distância psíquica não se manifestou como raiz da incerteza no processo de internacionalização das empresas aqui referidas. Todavia, como prevê a "revisita" ao Modelo de Uppsala, que tal raiz pode se concretizar com a falta de relacionamento em redes, as empresas analisadas anularam essa raiz engajando-se em redes externas de relacionamento. Para tanto, têm contado com a preocupação do projeto de procurar meios para instaurar/solidificar relacionamentos entre as afiliadas e entes externos do mesmo setor. Com isso, visa-se a evitar que o insucesso da internacionalização se torne o ônus pago pela falta de relacionamentos em redes (liability of outsidership).

Ressalta-se, entrementes, que a aprendizagem experiencial adquirida pelas empresas nos diferentes mercados é o que tem motivado a busca por inovação para competir internacionalmente. Enquanto vantagem competitiva, a inovação justifica o dispêndio das firmas para criar seus próprios centros de P\&D, ou formar parcerias com empresas estrangeiras tecnologicamente mais avançadas. 


\section{CONCLUSÕES, PROPOSIÇÃO E RECOMENDAÇÕES}

A seguir, apresentam-se as conclusões do estudo e a proposta de um modelo comportamental evolutivo para a internacionalização de PMEs brasileiras fabricantes de produtos de HPPC. Ao final, recomendações são sugeridas para futuras pesquisas sobre o tema, relacionadas com esse ramo de negócio.

\subsection{Conclusões}

De acordo com a análise dos casos aqui apresentados, não foi observado o uso de um modelo particular para a entrada das empresas em mercados estrangeiros. Ou seja, os modos como as empresas se inseriram internacionalmente apresentam algumas similaridades, mas também dessemelhanças. Entretanto, o Modelo de Uppsala é o framework que, grosso modo, mostra alguma similaridade com os processos analisados (ex.: importância do engajamento da firma em redes de relacionamento, comprometimento da empresa internacionalizada com os mercados externos e gradualismo na cadeia de estabelecimento).

A distância psíquica, que teve sua importância minorada pelos autores após a "revisita" ao Modelo, foi completamente ignorada pelas empresas analisadas e não foi um obstáculo para sua entrada no mercado internacional. Todavia, vale reiterar o caráter universal do uso de produtos de HPPC.

Conclusivamente, as empresas não fizeram uso de um modelo específico para se internacionalizar; tampouco a literatura afim ao tema explica plenamente os casos investigados. Razão essa que levou os autores a fazer a proposição de um modelo comportamental evolutivo para a internacionalização de PMEs brasileiras fabricantes de produtos de HPPC, consoante à descrição dada a seguir.

\subsection{Proposta de modelo comportamental evolutivo de internacionalização}

A Figura 1 esquematiza a proposta de modelo, cuja utilização ocorre em seis etapas: 1) as empresas vinculam-se à instituição representante do setor brasileiro de HPPC; 2) essa instituição recebe suporte governamental para incentivar a internacionalização das empresas afiliadas; 3) o foco das empresas se volta à obtenção de vantagens competitivas através do uso de novas tecnologias, empreendimento em iniciativas inovadoras e/ou uso de know-how - a partir da aquisição dessas vantagens, cada empresa passa a objetivar inserir-se internacionalmente, para tanto e a seu modo, as empresas procuram engajar-se em redes externas de relacionamento (ex.: distribuidores com conhecimento dos mercados externos); 4) quando, e se necessário, as empresas envidam esforços para adaptar a produção às exigências dos mercados; 5) o processo de internacionalização de cada empresa se concretiza e se torna uma atividade constante à medida que ela aprende e se compromete com os mercados estrangeiros em que atua; 6) as experiências resultantes do mencionado comprometimento e da aprendizagem com os mercados internacionais são repassadas para os demais participantes do projeto (rede doméstica de relacionamento).

Cabe ressaltar que o modelo proposto não determina com quem as empresas devem formar redes de relacionamento, tampouco determina o tipo de exportação (direta ou indireta) a ser inicialmente utilizado, porém, admite que a cadeia de estabelecimento possa ser queimada/saltada e que a variedade das ações empresariais represente um fator de enriquecimento para o grupo, pois a experiência de uma empresa relacionada com a via de entrada e a consolidação de sua presença em determinado mercado pode vir a ser um estímulo para que outras empresas se valham dessa mesma via para inserir-se no mesmo ou em outros mercados. 
MODELO COMPORTAMENTAL EVOLUTIVO DE INTERNACIONALIZAÇÃO

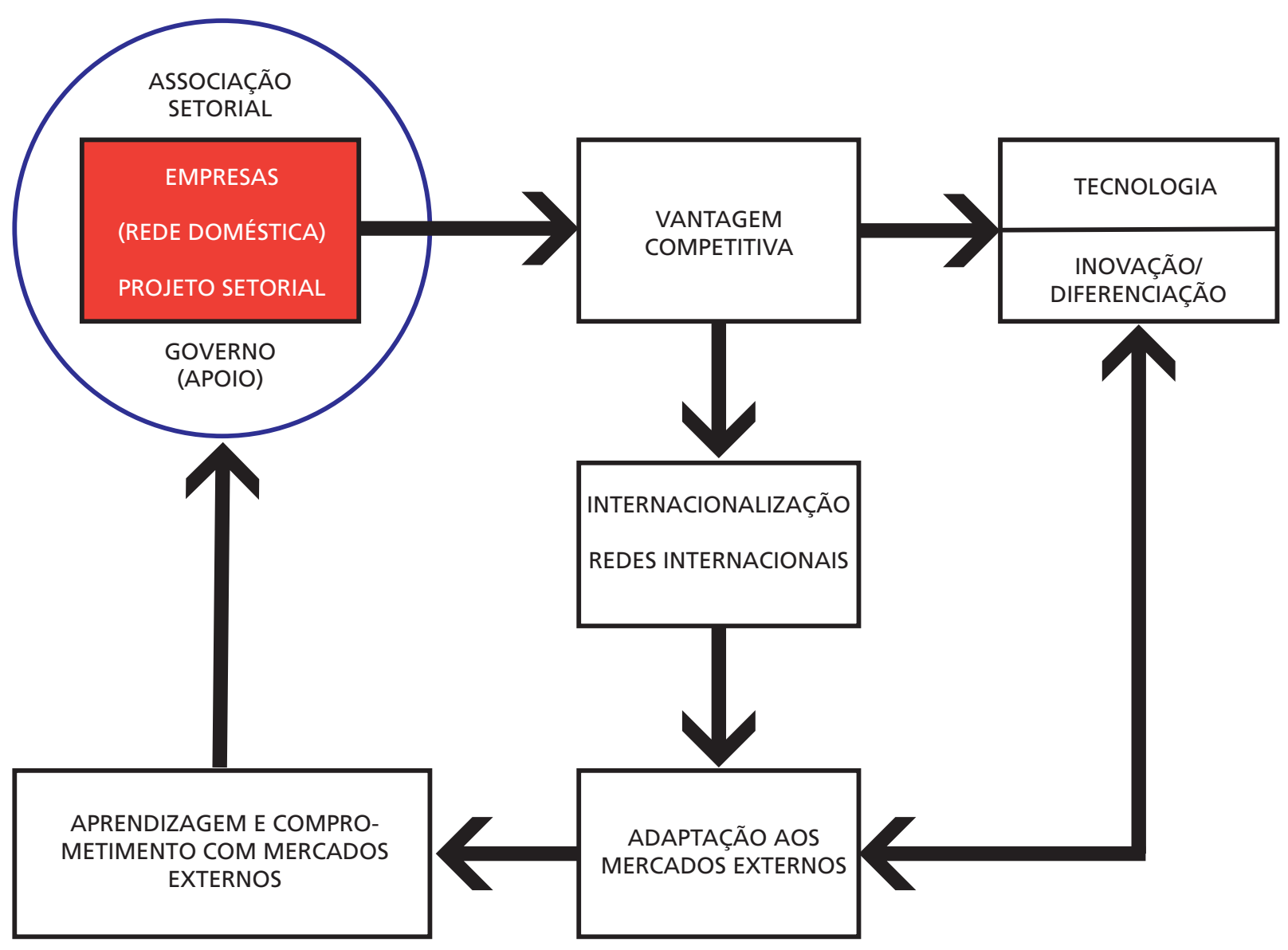

Figura 1: Modelo de internacionalização

Fonte: Elaboração dos autores.

O modelo se adjetiva de comportamental evolutivo, porque depende de como as empresas se comportam técnico e administrativamente na condução do processo de internacionalização, que evolui ao passo que as empresas se empenham em inovar na produção, adequando-se às demandas externas e diferenciando-se da concorrência para melhor competir e sobreviver em diferentes mercados. Por último, o modelo proposto não assume caráter universal e limita-se no tempo; ou melhor, continua válido enquanto o atual ambiente/contexto socioeconômico for mantido.

\subsection{Recomendações para estudos futuros}

O caráter exploratório do estudo torna-se um empecilho à generalização quanto ao uso do modelo proposto para a internacionalização de PMEs pertencentes a qualquer ramo de negócio. Por um lado, no entanto, admite-se a possibilidade de o modelo poder ser utilizado para a internacionalização de PMEs fabricantes de outros produtos, cujo uso seja universal, a exemplo de calçados e de vestuário. Por outro lado, sabe-se que firmas de grande porte também integram o Beautycare Brazil. Sendo assim, recomenda-se 
que se pesquise o projeto setorial como um todo, considerando todos os estratos empresariais, a fim de verificar diferenças e similaridades nos processos de internacionalização das PMEs e das empresas multinacionais (EMNs). Sugere-se, ainda, que sejam feitas pesquisas acerca: 1) da formação de parcerias entre fabricantes de HPPC para competir no mercado externo; 2) do uso conjunto de estratégias para reduzir custos (ex.: compras conjuntas de matérias primas); e 3) da replicação da proposta deste trabalho em cadeias produtivas globais.

\section{REFERÉNCIAS}

ABIHPEC - Associação Brasileira da Indústria de Higiene Pessoal, Perfumaria e Cosméticos. Panorama do Setor Higiene Pessoal, Perfumaria e Cosméticos. São Paulo, 12 abril 2010. Disponível em: <http://www.abihpec.org.br/conteudo/ Panorama_do_setor_20092010_Portugues_1 2_04_10.pdf >. Acesso em: 10 out. 2010.

Institucional. 2011. Disponível em: www. abihpec.org.br/institucional/. Acesso em: 12 mar. 2013.

ALBUQUERQUE LLORENS, Francisco. Desenvolvimento Econômico Local: Caminhos e Desafios para a Construção de uma Nova Agenda Política. $1^{\text {a }}$ ed. Rio de Janeiro: BNDES, 2001.

AULAKH, P. S.; KOTABE, M.; TEEGEN, H. Export Strategies and Performance of Firms from Emerging Economies: Evidence from Brazil, Chile, and Mexico. Academy of Management Journal, v. 43, n. 3, p. 342-361, 2000.

BEAUTYCAREBRAZIL. Catálogo (Empresas participantes do programa). São Paulo: Beautycare Brazil, 2011.

BNDES - Banco Nacional de Desenvolvimento Econômico e Social. Porte de Empresa. Disponível em: <http://www.bndes.gov.br/SiteBNDES/bndes/ bndes_pt/Navegacao_Suplementar/Perfil/porte. html >. Acesso em: 01 dez. 2011.
CHIAO, Yu-Ching; YANG, Kuo-Pin. Internationalization, Intangible assets and Taiwanese SMEs' performance: Evidence of an Asian newly-industrialized economy. African Journal of Business Management, v. 5(3), p. 641-655, 04 fev. 2011. Disponível em: http://www. academicjournals.org/AJBM. Acesso em: 20 maio 2011.

COSH, A. D.; HUGHES, A.; SINGH, A. Openness, Financial Innovation, Changing Patterns of Ownership, and the Structure of Financial Markets (Units 4 \& 8). In: International Finance - Readings. London: Centre for International Education in Economics - University of London, 1992.

DANIELS, J. D.; RADEBAUGH, L. H. International Business: Environments and Operation. Nova York: Addison-Wesley, 1998.

DUARTE, Rosália. Pesquisa Quantitativa: Reflexões sobre o Trabalho de Campo. Cadernos de Pesquisa, n. 115, p. 139-154, março-2002.

FORSGREN, Mats; HAGSTRÖM, Peter. Ignorant Internationalization? The Uppsala Model and Internationalization Patterns for Internet-related firms. 2005. Disponível em: < http://www.snee.org/filer/ papers/361.pdf. > Acesso em: 05 ago. 2010.

GAO, G. Y.; MURRAY, J.; KOTABE, M.; LU, J. A "Strategy Tripod" perspective on export behaviors: evidence from domestic and foreign firms based in an emerging 


\section{REFERÊNCIAS}

economy. Journal of International Business Studies, 1-20. Washington (DC): Academy of International Business, 2009.

GHEMAWAT, Pankaj. Distance Still Matters: The Hard Reality of Global Expansion. Harvard Business Review, Sept./2001. Disponível em: <http://lapetus. uchile.cl/lapetus/archivos/12233894 >. Acesso em: 10 set. 2011.

The Globalization of Markets. In: Globalization Note Series, 2010. Disponível em: http://www.aacsb.edu/resources/globalization/ globecourse/contents/readings/globalization-ofmarkets.pdf. Acesso em: 18 dez. 2012.

HANSSON, G.; SUNDELL, H.; ÖHMAN, M. The new modified Uppsala model - Based on an anomalistic case study at Malmberg Water AB. Kristianstad: Kristianstad University, 2004.

HEMAIS, Carlos A.; HILAL, Adriana. O Processo de Internacionalização na Ótica da Escola Nórdica: Evidências Empíricas em Empresas Brasileiras. RAC - Revista de Administração Contemporânea, v.7, n. 1, p. 109-124, Jan./Mar./2003.

JOHANSON, Jan; VAHLNE, Jan-Erik. The Internationalization Process of the Firm: A model for knowledge development and increasing market commitments. Journal of International Business Studies. Washington (DC): v. 8, p. 23-32, Spring/ Summer 1977.

The Uppsala internationalization process model revisited: From liability of foreignness to liability of outsidership. Journal of International Business Studies. Washington (DC): vol. 40, p. 1411-1431, 2009.
KATZ, Bruce; BRADLEY, Jennifer. Cleveland Region has built the Foundation for Increased Exports and New Jobs. Export Nation, n. 6, ago. 08, 2010. Disponível em: http://www.brookings.edu/opinions/2010/0808_ cleveland_exports_katz_bradley.aspx Acesso em: 20 ago. 2010.

KIRK, Ron. Trade Agreements will help create exportsupported jobs in America. The White House Blog. out. 04, 2011. Disponível em: <http://www.whitehouse.gov/ blog/2011/10/04/trade-agreements-will-help-createexportsupported-jobs-america> Acesso em: $10 \mathrm{dez}$. 2011.

KUO, Chin-Lung; FANG, Wen-Chang. Psychic Distance and FDI Location Choice: Empirical Examination of Taiwanese Firms in China. Asia Pacific Management Review, v. 14, n. 1, p. 86-106, mar. 2009.

LARIMO, J. Internationalisation of SMEs: Two Case Studies of Finnish Born Global Firms. In: BLOMSTERMO, A: SHARMA, D. D. (eds.): Learning in the Internationalisation Process of the Firms. Northampton (mass.): Edward Elgar Publishing, Inc., 2003.

MADURA, Jeff. International Financial Management, $10^{\text {th }}$ ed. Cincinnati: South-Western College Publishing, 2011.

REZENDE, Sérgio Fernando Loureiro. Interdependence and the Internationalisation Process of MNCs: Uniformity, Direction and Rhythm. In: XXVIII ENANPAD - Encontro Nacional dos Programas de Pós-Graduação em Administração. Curitiba: ANPAD, 2004.

ROWDEN, Robert W. Research Note: How a Small Business Enters the International Market. Thunderbird International Business Review. Hoboken (NJ): John Wiley \& Sons, v. 43(2), p. 257-268, Mar./Abr./2001. 


\section{REFERÊNCIAS}

SEBRAE - Serviço Brasileiro de Apoio às Micro e Pequenas Empresas. Critérios de estratificação de empresas segundo o tamanho. Disponível em: $\quad$ http://www.sebrae.com.br/br/pesquisa_ exportacao4/definicoes.asp. Acesso em: 20 set. 2011.

TEIXEIRA JR., Job Rodrigues; GALINARI, Rangel; MONTANO, Paulo Fernandes; SILVA, Juliana Generoso da. Indústrias Tradicionais de Bens de Consumo no Brasil: Desafios e Oportunidades. BNDES 60 Anos: Perspectivas Setoriais. 2012.
Disponível em: http://www.bndes.gov.br/SiteBNDES/ export/sites/default/bndes_pt/Galerias/Arquivos/ conhecimento/livro60anos_perspectivas_setoriais/ Setorial60anos_VOL2BensConsumo.pdf. Acesso em: 18 jul. 2013.

TREVISAN, Leonardo Nelmi. Internacionalização de Empresas Brasileiras: Uma Aplicação do "Modelo de Uppsala". eGESTA - Revista Eletrônica de Gestão de Negócios (UNISANTOS), v. 5, n. 3, ju.-set./2009. Disponível em: www.unisantos.br/ mestrado/gestao/ egesta/artigos/184.pdf. Acesso em: 10 abr. 2011. 